\title{
Special patients, specialised care
}

\section{Arnold G Vulto}

In most European countries, pharmacy students spend some time in hospital pharmacies to learn more about the different forms of practice they can choose once qualified as a pharmacist. Also, in our pharmacy, we welcome several students each year for an 8-10 week internship. Over the years we have developed an intense programme to show these students how the theory of their studies is applied in the practice of hospital pharmacy. At the end of the internship we ask them to write a brief essay, answering four questions:

- Describe the concepts behind the management of our hospital pharmacy

- How can you justify the employment of 30 pharmacists (which to Dutch standards is quite high for a 1200 bed university hospital)?

- Please provide some recommendations on how we can do a better job

- Can you describe some essential differences between community pharmacy and hospital pharmacy?

What surprises us almost every time is how little sixth year pharmacy students even after 8 weeks of internship - have thought about some of the principles of hospital pharmacy. We all know that the organisational concepts behind a hospital pharmacy are quite different from a community pharmacy. The difference in scale, I think, is rather irrelevant. We have large community pharmacies and small hospital pharmacies, so there is overlap. Most community pharmacies are very much prescription driven, in contrast with most hospital pharmacies. Our 'clients' are predominantly nurses, doctors and medical departments, although the focus of our care is the patient. Hospital pharmacists play a more dominant role in determining the assortment of drugs we have, for example, via a drug formulary committee. What most students have perceived are differences in complexity of patients and drug treatment.

Correspondence to Arnold G Vulto, Editor-in-Chief EJHP Practice \& Science, Department of Hospital Pharmacy, Erasmus University Medical center, Rotterdam 3015 CE, Netherlands; editor.ejhp@bmjgroup.com
An important feature of hospital pharmacy is the specialised pharmaceutical care we offer to sometimes very special patients that may not be found in standard textbooks.

It is therefore very timely that the European Association of Hospital Pharmacists (EAHP) has chosen 'Special Patient Groups - hospital pharmacists creating standards of care' as a theme for the 2012 annual congress. The congress programme highlights traditional special groups, such as children and geriatric patients but newer concepts will also be discussed. To mention just a few: care after transplantation, the limits of treatment, compassionate drug use, the difficulties in assessing the real value of new treatments and the potential of genetic screening of patients. Although we expect well above 2000 hospital pharmacists to participate in the conference, the majority of EAHP members will be dependent on the journal to savour some of the highlights of the congress. In this issue, we begin with a few previews of the programme, and in the next issue we will report further on the congress. Most presenters have agreed to write for the journal, and most seminars will be made available online for perusal after the congress.

An important group of 'special patients' are the elderly. They are usually more sensitive to drug effects, regularly use several drugs (five or more) at the same time and the older they get, the more organ functions, such as the kidneys, become compromised. As a result, the majority of patients admitted to hospital for drug side effects via the emergency department are aged over 65 years. An illustrative study from Ireland that was published last year in the Archives of Internal Medicine ${ }^{1}$ showed how a new STOPP algorithm (Screening Tool of Older Persons' potentially inappropriate prescriptions) can predict (and therefore also avoid) such disasters. This excellent study offers the possibility for (hospital) pharmacists to take better control over inappropriate medicine use by elderly patients.

A specific problem with special patient groups is that often no medicines have been licensed for such a particular group. Although we usually know how to choose and prescribe drugs and the doses needed, based on our collaborative experience and possibly also published studies, the situation is not ideal. The reason is wider than just lack of knowledge. The current situation around clinical trials approval and drug legislation is counterproductive to getting drugs researched and licensed for small populations. Drug licensing is in the hands of a license holder, almost exclusively the pharmaceutical industry. Drug research and licensing is very costly, and companies will look at cost effectiveness before embarking on a clinical study and applying for a license extension to smaller patient groups. I am curious what kind of solutions the speakers of the seminar (Compassionate use and off-label medicines) will present for this dilemma.

An important new feature in our journal is that all abstracts for poster and oral presentations that have been accepted by the congress Scientific Committee will be published in EJHP. Hence these abstracts will be easily accessible for all members, and not just those attending the congress.

If you have the privilege of attending the 2012 EAHP congress you will be able to savour the beauty of Milan as a city and also replenish your hospital pharmacy knowledge. I am proud that we as a journal can also serve the less fortunate who have to stay home. Someone has to look after our patients when the others are away! It is my sincere conviction that all EAHP members should benefit from all of the educational activities that EAHP is offering, and our journal plays a pivotal role in that process.

In this way, we can offer you the kind of continuous education that is required to make sure you offer your patients the best specialised pharmaceutical care, based on the latest insights developed by our profession.

Competing interests None.

Provenance and peer review Not commissioned; not internally peer reviewed.

Accepted 30 January 2012

European Journal of Hospital Pharmacy 2012;19:65-66.

doi:10.1136/ejhpharm-2011-000086

\section{Reference}

1. Hamilton H, Gallagher P, Ryan C, et al. Potentially inappropriate medications defined by STOPP criteria and the risk of adverse drug events in older hospitalized patients. Arch Intern Med 2011;171:1013-19 


\section{EAHP Statement on Hospital Pharmacy specialisation}

Hospital Pharmacists are key stakeholders in medication management in hospitals. This is a role which encompasses the entire way in which medicines are selected, supplied, quality assured, prescribed, and administered with the overall aim being to improve the safety and quality of all medicine related processes affecting patients.

To achieve this, a hospital pharmacist must be able to operate in a complex hospital setting and work collaboratively within multidisciplinary healthcare teams in order to provide the best treatment for patients in acute situations or receiving care in specialised ambulatories.

The basic education of 5 years for pharmacists as required by the European Directive on Mutual Recognition of Professional Qualifications 2005/36/EC does not provide sufficient competencies to work independently in the hospital environment. Additional competencies are necessary to fully understand the processes in hospitals and to manage the specific requirements of certain patient groups (i.e. paediatrics, oncology, intensive care, rare diseases.) A comprehensive list of the competencies necessary to improve hospital pharmacy outcomes has been produced by EAHP with the support of the EU funded Pharmine project (http://www.eahp.eu/Advocacy/Hospital-pharmacyspecialisation).

EAHP believes that post graduate education in the hospital setting of at least 3, preferably 4 years with a final assessment of individual competency is essential to ensure that where pharmacists are providing front office hospital pharmacy services, patients benefit from the highest levels of expertise.

Many EU Member States have already formally recognised the need for specialisation in hospital pharmacy and the way in which this improves patient care. However, a lack of EU level mutual recognition of Hospital Pharmacy as structured specialisation creates substantial differences in the qualifications of pharmacists working in hospitals across Europe. It also undermines the efforts of certain European countries to advance the level of pharmaceutical care in the hospital setting and creates inequalities in patient access to the best possible care.

The review of the EU Directive on Mutual Recognition of Professional Qualifications provides an opportunity to address these issues. As an advocate of patient safety and in particular the safe and effective management of medication in hospitals, EAHP firmly asks that the European rules on professional mobility be updated to introduce Hospital Pharmacy as a mutually recognised speciality. This should be done in a way which is comparable to what has already been implemented for physicians under similar conditions. We believe that this is an essential step forward to ensure that all patients in acute situations benefit from pharmaceutical care that is underpinned by the highest levels of knowledge, skills, and experience. 